\title{
Role of CD8+ lymphocytes in chronic rejection of transplanted hearts
}

\author{
Michael P. Fischbein, MD, PhD ${ }^{a, b}$ \\ James Yun, MD, PhD ${ }^{a, c}$ \\ Hillel Laks, MDa \\ Yoshihito Irie, MDa \\ Michael C. Fishbein, MDc \\ Benjamin Bonavida, $\mathrm{PhD}^{\mathrm{b}}$ \\ Abbas Ardehali, MD ${ }^{a^{*}}$
}

From the Division of Cardiothoracic Surgery, Department of Surgery, ${ }^{\text {a }}$ Department of Microbiology, Immunology, and Molecular Genetics, ${ }^{b}$ and Department of Pathology and Laboratory Medicine, University of California, Los Angeles, UCLA Medical Center, Los Angeles, Calif.

Received for publication May 1, 2001; revisions requested July 27, 2001; revisions received Aug 16, 2001; accepted for publication Aug 31, 2001

Address for reprints: Abbas Ardehali, MD, UCLA Medical Center, Department of Surgery, Division of Cardiothoracic Surgery, CHS 62-246, 10833 LeConte Blvd, Los Angeles, CA 90095 (E-mail: aardehali@ mednet.ucla.edu).

*Recipient of the Second Alfred Blalock Research Scholarship Award, The American Association for Thoracic Surgery.

J Thorac Cardiovasc Surg 2002;123:803-9

Copyright (C) 2002 by The American Association for Thoracic Surgery

$0022-5223 / 2002 \$ 35.00+0 \quad \mathbf{1 2} / \mathbf{1} / \mathbf{1 2 0 0 0 8}$

doi:10.1067/mtc. 2002.120008
Background: The contribution of $\mathrm{CD} 8^{+}$lymphocytes to the pathogenesis of cardiac allograft vasculopathy, or chronic rejection in heart transplants, remains undefined. We used both major histocompatibility complex class I mismatched and major histocompatibility complex class II mismatched models of cardiac allograft vasculopathy to characterize the role of $\mathrm{CD}^{+}$lymphocytes in the development of cardiac allograft vasculopathy.

Methods: Donor hearts from B10.A mice were transplanted into B10.BR recipients (major histocompatibility complex class I mismatched). Donor hearts were harvested at 1,7,14, and 30 days after transplantation and (1) quantitated morphometrically for lesion development, (2) stained immunohistochemically, or (3) digested for isolation of graft-infiltrating cells. The cytotoxic phenotype of graft-infiltrating $\mathrm{CD}^{+}$lymphocytes was determined with flow cytometry. Intracellular cytokine staining of $\mathrm{CD} 8^{+}$and $\mathrm{CD} 4^{+}$lymphocytes for interleukin 2 , interferon $\gamma$, interleukin 4, and interleukin 10 was performed with 2-color flow cytometry. Finally, B6.C$\mathrm{H} 2^{\mathrm{bm} 12}$ donor hearts were transplanted into either C57BL/6 wild-type (major histocompatibility complex class II mismatched) or CD8 -/- knockout recipients and examined for the development of cardiac allograft vasculopathy.

Results: In the major histocompatibility complex class I mismatched model, CD8 ${ }^{+}$ lymphocytes were the predominant T-lymphocyte subset that infiltrated the allografts and demonstrated markers of activation. The intracellular cytokine-staining assay demonstrated that $\mathrm{CD} 8^{+}$lymphocytes were the primary sources of allograft interleukin 2 and interferon $\gamma$. Intimal lesions developed in the allografts by day 14 $(12.0 \% \pm 4.0 \%)$ and further increased by day $30(44.0 \% \pm 5.0 \%)$. In the major histocompatibility complex class II mismatched model, the donor hearts in the CD8 -/- knockout recipients had substantially less severe intimal lesions when compared with the donor hearts in wild-type recipients $(19.0 \% \pm 6.0 \%$ vs $50.0 \% \pm 7.0 \%$, respectively; $P<.05)$.

Conclusions: In both major histocompatibility complex class I and II mismatched models, $\mathrm{CD} 8^{+}$lymphocytes contribute significantly to chronic rejection. The findings of this study suggest that control of chronic rejection requires interventions directed at $\mathrm{CD} 8^{+}$lymphocytes.

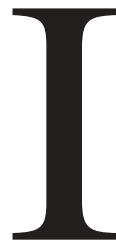

mproved perioperative care and more effective immunosuppression regimens have dramatically improved the short-term outcome of heart transplantation. However, chronic rejection, or cardiac allograft vasculopathy $(\mathrm{CAV})$, remains the major obstacle to the long-term survival of heart transplant recipients. ${ }^{1}$ Although 3-hydroxy-3-methylglutaryl coenzyme A reductase (HMG-CoA) inhibitors have been reported to decrease the severity of 
intimal proliferation, ${ }^{2}$ pharmacologic therapies have generally been ineffective in preventing CAV development. Because of the diffuse nature of the intimal lesions, revascularization procedures are seldom used. Retransplantation remains a therapeutic option; however, both poor short-term outcomes compared with the initial transplantation ${ }^{3}$ and scarcity of donor organs pose an ethical dilemma in most transplant centers.

CAV is a complex multifactorial process. Although the contribution of alloantigen-independent processes to the development of CAV is becoming increasingly evident, ${ }^{4}$ it is generally accepted that the cellular immune system participates in the pathogenesis of CAV. ${ }^{5-8}$ However, the role of Tlymphocyte subsets, and specifically the role of $\mathrm{CD} 8^{+}$ lymphocytes in the development of CAV, is incompletely defined. Prior studies have yielded conflicting results on the role of $\mathrm{CD}^{+}$lymphocytes in chronic rejection. Allan and colleagues ${ }^{9}$ have demonstrated the importance of $\mathrm{CD} 8^{+}$lymphocytes in chronic rejection using an inbred porcine major histocompatibility complex (MHC) class I mismatch model in which intimal proliferation was abrogated after anti-CD8 antibody therapy. In contrast, Clarke-Forbes and coworkers ${ }^{10}$ reported that $\mathrm{CD} 8^{+}$lymphocyte depletion did not alter the severity of chronic rejection in a rat MHC class I and class II mismatched model. Similarly, using a murine carotid artery loop model, Shi and colleagues ${ }^{5}$ reported that $\mathrm{CD}^{+}$ lymphocytes were not involved in neointimal proliferation.

Our laboratory has previously characterized 2 murine models of CAV without immunosuppression in which the donor and recipient strains differ at either (1) MHC class I or (2) MHC class II antigens. ${ }^{11-13}$ Using these 2 models, we sought to define the role of $\mathrm{CD}^{+}$lymphocytes in CAV. In the MHC class I mismatched model we studied (1) the temporal pattern of $\mathrm{CD}^{+}$lymphocyte infiltration in relationship to CAV development, (2) the activation status of infiltrating CD8 ${ }^{+}$lymphocytes, and (3) the contribution of $\mathrm{CD}^{+}$lymphocytes to the production of proinflammatory cytokines, including interferon (IFN) $\gamma$. Given the availability of transgenic strains in our MHC class II mismatched model, we studied the effect of genetic absence of $\mathrm{CD} 8^{+}$ lymphocytes on CAV development. The results of this study demonstrate an important role for $\mathrm{CD}^{+}$lymphocytes in chronic rejection. More importantly, these findings yield some insight into the mechanism of failure of costimulatory blockade therapy in preventing chronic rejection.

\section{Methods}

Animals

B10.A, B10.BR, B6.CH-2 ${ }^{\text {bm12 }}$, and C57BL/6 (wild-type, CD8 -/knockout) strains of female mice (7-11 weeks old) were purchased from Jackson Laboratories and housed under conventional conditions. They were fed rodent chow (Purina Mills, Inc, St Louis, Mo) and water ad libitum. The B10.A and B10.BR strains of mice differ at 2 loci of MHC class I antigens but are matched at other loci. The B6.CH-2 $2^{\text {bm12 }}$ and C57BL/6 strains of mice differ in one locus of MHC class II antigens but are matched at other loci. All animals received humane care in compliance with the "Principles of Laboratory Animal Care" and the "Guide for the Care and Use of Laboratory Animals" prepared by the Institute of Laboratory Animal Resources and published by the National Institutes of Health.

\section{Transplantation}

The intra-abdominal heterotopic heart transplantation was performed with the technique previously described by Corry and colleagues. ${ }^{14}$ Briefly, through a midline abdominal incision, the donor aorta was anastomosed to the recipient infrarenal abdominal aorta, and the donor pulmonary artery was anastomosed to the inferior vena cava with 10-0 nylon sutures. The donor ischemia time was approximately 45 minutes. Function of the allografts was assessed through abdominal palpation and scored on a scale of 0 to 4 ( 0 indicates absence of contractions and 4 indicates normal beating).

\section{Experimental Groups}

In the MHC class I mismatched group B10.A strain mouse hearts were transplanted into B10.BR recipients and harvested at days 1 , 7,14 , and 30 , respectively ( $\mathrm{n}=6$ each group). In the isograft groups B10.BR mouse hearts were transplanted into B10.BR recipients and removed at days $1,7,14$, and 30 ( $n=6$ each group). Control B10.A and B10.BR hearts were also excised (day 0) and examined for infiltration of inflammatory cells and constitutive expression of activation markers ( $\mathrm{n}=6$ each group). No immunosuppression was administered.

In the MHC class II mismatched group B6.CH-2 $2^{\text {bm12 }}$ mouse hearts were transplanted into $\mathrm{C} 57 \mathrm{BL} / 6$ wild-type control recipients $(n=6)$ or CD8 $-/-$ knockout recipients $(n=6)$. In the isograft groups C57BL/6 mouse hearts were transplanted into C57BL/6 recipients $(n=6)$. All recipients were harvested at 24 days. No immunosuppression was administered.

\section{Immunostaining and Morphometric Analysis}

The transplanted and native hearts were explanted in all animals. The harvested hearts were fixed in liquid nitrogen embedded in OCT compound and kept at $-70^{\circ} \mathrm{C}$. The primary antibodies were as follows: rat anti-mouse $\mathrm{CD} 4$ monoclonal antibody clone GK1.5; rat anti-mouse CD8a monoclonal antibody clone 53-6.7; rat anti-mouse $\mathrm{CD} 11 \mathrm{~b}$ (Mac-1) clone M1/70 and rat anti-mouse MOMA-2 monoclonal antibody for monocytes/macrophages; rat anti-mouse CD25 monoclonal antibody clone 7D4 for interleukin (IL) 2R; and anti-mouse $\alpha$-smooth muscle actin monoclonal antibody clone 1A4 for smooth muscle cells. All primary antibodies were purchased from PharMingen (San Diego, Calif), with the exception of $\alpha$-smooth muscle actin antibody (Sigma Chemical Co, St Louis, Mo).

Immunohistochemistry was performed on 5- $\mu \mathrm{m}$-thick cryostat sections with the use of an avidin-biotin-peroxidase technique (Vector Laboratories, Inc, Burlingame, Calif), with 3,3'diaminobenzidine as the chromogen. Sections were incubated with the Avidin-Biotin Complex Solution, Vectastain Elite ABC kit (Vector Laboratories, Inc). 3,3'-Diaminobenzidine was applied and subsequently counterstained with Harris hematoxylin. 
The perivascular and vascular region was scored by 2 blinded observers on a scale of 0 to 4 ( 0 , no staining; 1 , scattered individual cells; 2 , focal clusters of cells; 3 , multifocal clusters of cells; and 4, diffuse clusters of cells).

Hematoxylin and eosin stains were performed for routine examination and scoring of acute cellular rejection by using the International Society for Heart and Lung Transplantation grading system. Elastin van Gieson staining was performed for morphometric analysis of arterial intimal proliferation. The morphometric analysis method previously described by Armstrong and colleagues ${ }^{15}$ was used. The areas of the neointima, media, and lumen were measured with Optimas 6 software by Media Cybernetics. The neointima was defined as the area bound by the internal elastic lamina and the lumen. The media was defined as the region between the internal and external elastic membranes. The lumen was defined as the clear region in the vessel. Multiple sections from the middle of the heart were used for analysis. Vessels greater than $80 \mu \mathrm{m}$ were measured. An average of 10 vessels per heart were measured.

\section{Flow Cytometric Analysis}

Allografts were homogenized and digested with $10 \mu \mathrm{g} / \mathrm{mL}$ collagenase D (Sigma Chemical Co) for 2 hours. The homogenate was passed through a nylon strainer, and red blood cells were lysed with red blood cell lysing buffer (Sigma Chemical Co), washed, and resuspended in phosphate-buffered saline solution. The recipient's splenocytes were isolated with a nylon cell strainer, and red blood cells were lysed and subsequently washed. Cells were incubated with Cychrome-labeled CD8 monoclonal antibody, phycoerythrin (PE)-labeled CD44 monoclonal antibody, and fluorescein isothiocyanate (FITC)-labeled CD62 monoclonal antibody for 30 minutes; washed; and analyzed with a COULTER EPICS XLMCL Flow Cytometer (Coulter Corporation, Hialeah, Fla). All antibodies were purchased from PharMingen. Data were presented as percentages of cells with positive staining calculated as the difference between the sample's fluorescence and background nonspecific fluorescence. The cytotoxic phenotype was defined as CD8 high, CD44 high, CD62 low.

The intracellular cytokine-staining assay was used to determine the intragraft cytokine profile, identify the cytokine source, and confirm T-lymphocyte activation. For intracellular cytokine evaluation, donor heart graft-infiltrating cells were isolated (1-2 $\times$ $10^{6} / \mathrm{mL}$ ) and subsequently stimulated with PharMingen Activation Cocktail $(10 \mu \mathrm{L} / 6 \mathrm{~mL}$; containing phorbol myristate acetate, ionomycin, and Brefeldin A) for 4 hours at $37^{\circ} \mathrm{C}$. Three separate experiments were performed at each time point. Only the donor hearts from the MHC class I mismatched model system were analyzed in this study. By using 2-color flow cytometric analysis, graft-infiltrating cells were double stained for cell-surface markers, as well as for intracellular cytokines. Specifically, the samples were stained for the presence of cell-surface antigens with FITClabeled anti-CD8 monoclonal antibody or FITC-labeled anti-CD4 monoclonal antibody for 30 minutes at $4^{\circ} \mathrm{C}$. Samples were washed, fixed, and permeablized with PharMingen Perm/Fix solution for 30 minutes at $4^{\circ} \mathrm{C}$. The cells were washed in permeablizing buffer and incubated with either PE-labeled IL-2 monoclonal antibody, PE-labeled IFN- $\gamma$ monoclonal antibody, PE-labeled IL-4
TABLE 1. Intimal proliferation in donor hearts $(n=6$ for all groups)

\begin{tabular}{lcllc}
\hline Group & Days & Donor & Recipient & Intimal thickening (\%) \\
\hline I & 1 & B10.A & B10.BR & $0.0 \pm 0.0$ \\
II & 7 & B10.A & B10.BR & $0.0 \pm 0.0$ \\
III & 14 & B10.A & B10.BR & $12.0 \pm 4.0^{*}$ \\
IV & 30 & B10.A & B10.BR & $44.0 \pm 4.9^{*}$ \\
V & 24 & bm12 & C57BL/6 & $50.0 \pm 7.0$ \\
VI & 24 & bm12 & CD8 -/- & $19.0 \pm 6.0 \dagger$ \\
\hline
\end{tabular}

${ }^{*} P<.05$ versus group $\mathrm{I}$.

$\dagger P<.05$ versus group $\mathrm{V}$.

monoclonal antibody, or PE-labeled IL-10 monoclonal antibody for 30 minutes at $4^{\circ} \mathrm{C}$. After 2 washes with permeablizing buffer, the cells were resuspended in phosphate-buffered saline. All antibodies were purchased from PharMingen. Data were presented as percentages of cells with positive staining calculated as the difference between the sample's fluorescence and background nonspecific fluorescence.

\section{Statistical Analysis}

All results were expressed as means \pm SEM. Statistical analyses were performed with a paired $t$ test.

\section{Results}

Histologic and Morphometric Analysis of Vascular Lesions in an MHC Class I Mismatched Model

All cardiac isografts and allografts had palpable contractions at the time of harvest. Cardiac allografts did not have an ISHLT rejection score of greater than $1 \mathrm{~B}$. Cardiac isografts (controls) did not show either acute rejection or CAV. Intimal thickening was first notable in allografts harvested at 14 days $(12.0 \% \pm 4.0 \%, P<.05$, Table 1$)$. The extent of intimal proliferation continued to increase when 30-day allografts were examined $(44.0 \% \pm 4.9 \%, P<.05$, Table 1 , Figure 1$)$.

Early vascular lesions were characterized by a predominately inflammatory cell component, with minimal smooth muscle cell proliferation. Specifically, T lymphocytes and macrophages infiltrated the cardiac allograft as early as 7 days. The majority of T lymphocytes at all time points were $\mathrm{CD}^{+}$lymphocytes, which were initially scattered through the interstitium. At 14 days after transplantation, $\mathrm{CD}^{+}$lymphocytes localized to the perivascular area (Figure 1, A). $\mathrm{CD}^{+}{ }^{+}$lymphocytes also demonstrated a similar pattern of perivascular localization by 14 days after transplantation. At early time points, monocytes-macrophages were localized in the interstitium and perivascular areas. In advanced lesions a large number of macrophages were found within the expanded intima and accounted for the majority of mononuclear cells within the lesion.

The cellular characteristics of the lesions described in this murine model of CAV appear similar to those identified in human models. The cellular constituents in human 

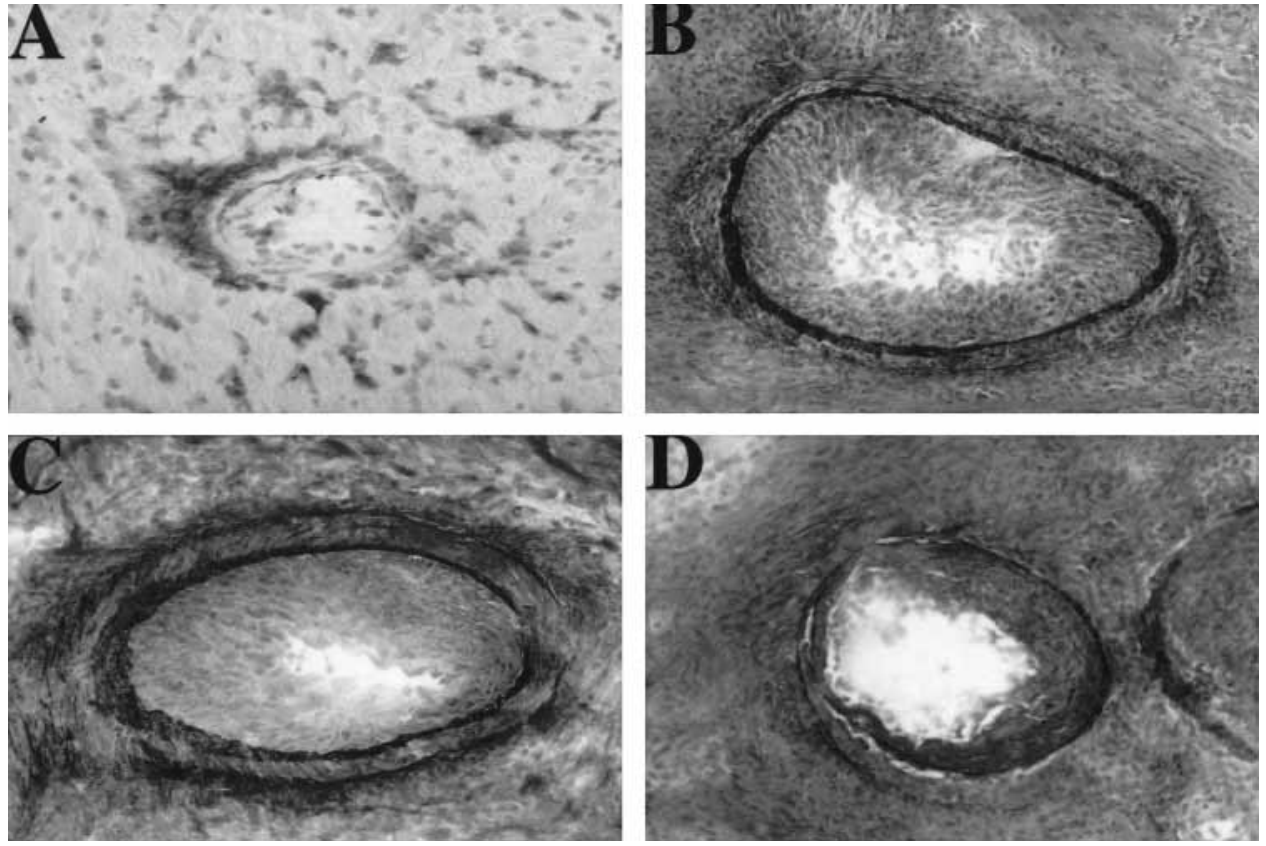

Figure 1. Immunostaining and intimal thickening in donor hearts transplanted into recipient mice. A, B10.A donors transplanted into B10.BR mice. There was an extensive amount of CD8+ $T$ lymphocytes localized primarily to the perivascular area. B, B10.A donors transplanted into B10.BR recipients had severe intimal lesions. C, B6.C-H2 ${ }^{\text {bm12 }}$ donor hearts transplanted into $\mathrm{C} 57 \mathrm{BL} / 6$ (wild-type) recipients also had severe intimal lesions. D, B6.C-H2 ${ }^{\text {bm12 }}$ donor hearts transplanted into CD8 -/- knockout recipients (CD4+ lymphocytes present) had less severe intimal lesions compared with the donor hearts transplanted into wild-type recipients.

TABLE 2. Graft-infiltrating cytotoxic CD8+ lymphocytes in transplanted hearts (B10.A donor hearts transplanted into B10.BR recipients)

\begin{tabular}{lcc}
\hline CD8 lymphocytes & $\begin{array}{c}\text { CD8 lymphocytes } \\
\text { Days }\end{array}$ & $\begin{array}{c}\text { demonstrating cytotoxicity markers } \\
\text { (CD8 }+ \text { graft-infiltrating cells) }\end{array}$ \\
\hline 7 & $34.0 \pm 3.0$ & $77.0 \pm 3.0$ \\
14 & $23.0 \pm 2.0$ & $94.0 \pm 1.0$ \\
30 & $18.0 \pm 4.0$ & $95.0 \pm 3.0$ \\
\hline
\end{tabular}

Data represent the percentage of $\mathrm{CD} 8^{+}$lymphocytes positive for markers associated with cytotoxicity (CD8 ${ }^{+} / \mathrm{CD} 44$ high/CD62 low) at each time point. Data are representative of 3 replicate experiments.

lesions have been described immunohistochemically as both $\mathrm{CD}^{+}$and $\mathrm{C}^{+}$lymphocytes, macrophages, and smooth muscle cells. ${ }^{16}$

\section{Activation Status of $\mathrm{CD8}^{+}$Lymphocytes}

To identify the activation status of the graft-infiltrating CD8 ${ }^{+}$lymphocytes, we looked at markers associated with $\mathrm{CD}^{+}$lymphocyte cytotoxicity $\left(\mathrm{CD} 8^{+} / \mathrm{CD} 62\right.$ low/CD44 high $)^{17}$ using flow cytometric analysis. The graft-infiltrating $\mathrm{CD}^{+}$lymphocytes expressed markers associated with cytotoxicity after transplantation (CD62 low/CD44 high) at all examined time points (Table 2).

\section{Relative Contribution of Graft-infiltrating $\mathrm{CD}^{+}$ Versus $\mathrm{CD8}^{+}$Lymphocyte Cytokine Staining}

The preceding experiments have established that the CD8 ${ }^{+}$ lymphocytes had localized to the perivascular area, were activated, and expressed markers of cytotoxicity before the development of CAV. Intracellular cytokine assays were performed on the graft-infiltrating $\mathrm{CD}^{+}$and $\mathrm{CD}^{+}$lymphocytes to determine their contribution to the intragraft cytokine profile. Representative cytokines of both $\mathrm{T}_{\mathrm{H}} 1$ (IL2 and IFN- $\gamma$ ) and $\mathrm{T}_{\mathrm{H}} 2$ (IL-4 and IL-10) type were used.

At all time points, $\mathrm{CD} 8^{+}$lymphocytes were the predominant graft-infiltrating T-lymphocyte subset in this MHC class I mismatched model (Table 3). Moreover, a greater percentage of $\mathrm{CD} 8^{+}$lymphocytes produced IL- 2 and IFN- $\gamma$ (Table 3 ). These findings suggest that $\mathrm{CD}^{+}$lymphocytes are the primary source of IFN- $\gamma$, which is known to cause CAV. ${ }^{18,19}$

Histologic and Morphometric Analyses of Vascular Lesions in an MHC Class II Mismatched Model

Similar to the MHC class I mismatched model, all cardiac allografts and isografts in the MHC class II mismatched 
TABLE 3. Intracellular cytokine staining of graft-infiltrating cells in transplanted hearts (B10.A donor hearts transplanted into B10.BR recipients)

\begin{tabular}{|c|c|c|c|c|c|c|}
\hline & \multicolumn{2}{|c|}{ Day 7} & \multicolumn{2}{|c|}{ Day 14} & \multicolumn{2}{|c|}{ Day 30} \\
\hline & CD4 & CD8 & CD4 & CD8 & CD4 & CD8 \\
\hline GIC (\%) & $0.3 \pm 0.1$ & $34.0 \pm 3.0$ & $1.0 \pm 0.8$ & $23.0 \pm 2.0$ & $3.0 \pm 3.0$ & $18.0 \pm 4.0$ \\
\hline IL-2 (\%) & $19.0 \pm 6.0$ & $25.0 \pm 7.0$ & $3.0 \pm 3.0$ & $7.0 \pm 1.0$ & $7.0 \pm 7.0$ & $12.0 \pm 4.0$ \\
\hline IFN (\%) & $8.0 \pm 5.0$ & $63.0 \pm 2.0$ & $9.0 \pm 6.0$ & $35.0 \pm 1.0$ & $5.0 \pm 5.0$ & $44.0 \pm 3.0$ \\
\hline IL-4 (\%) & $0.0 \pm 0.0$ & $0.0 \pm 0.0$ & $0.0 \pm 0.0$ & $0.0 \pm 0.0$ & $0.0 \pm 0.0$ & $0.0 \pm 0.0$ \\
\hline IL-10 (\%) & $0.0 \pm 0.0$ & $0.0 \pm 0.0$ & $0.0 \pm 0.0$ & $0.0 \pm 0.0$ & $0.0 \pm 0.0$ & $0.0 \pm 0.0$ \\
\hline
\end{tabular}

Data represent the percentage of each T lymphocyte subset positive for intracellular cytokine staining at each time point. Data are representative of 3 replicate experiments. GIC, Graft-infiltrating cells.

model had palpable contractions at the time of harvest at 24 days. The ISHLT rejection score of allografts ranged from $1 \mathrm{~B}$ to $3 \mathrm{~A}$. Cardiac isografts (controls) did not show either acute rejection or CAV. The immunohistochemical analysis of vascular lesions in the MHC class II model was similar to the MHC class I model. The cellular infiltrate of intimal lesions consisted of $\mathrm{CD}^{+} / \mathrm{CD}^{+}$lymphocytes, monocytesmacrophages, and smooth muscle cells. $\mathrm{CD} 4^{+}$and $\mathrm{CD} 8^{+}$ lymphocytes were both within the intimal lesions and in the perivascular areas in equal numbers. The extent of intimal lesions in the donor hearts transplanted into the wild-type recipients was $50.0 \% \pm 7.0 \%$ at 24 days (Table 1, Figure 1, $C)$. In contrast, the severity of intimal lesions in donor hearts transplanted into CD8 - $/-$ knockout recipients was substantially less at 24 days $(19.0 \% \pm 6.0 \%, P<.05$, Table 1 , Figure $1, D$ ). The absence of $\mathrm{CD} 8^{+}$lymphocytes was confirmed by means of flow cytometric analysis of both splenocytes of CD8 -/- knockout recipients and the graftinfiltrating cells of the donor hearts.

\section{Discussion}

In this study we used 2 nonimmunosuppressed models of $\mathrm{CAV}$ to further delineate the role of $\mathrm{CD}^{+}$lymphocytes during chronic rejection of vascularized cardiac allografts. The findings in this model illustrate that $\mathrm{CD}^{+}$lymphocytes (1) localize in the perivascular area before the development of intimal lesions, (2) express markers of cytotoxicity, and (3) produce proinflammatory cytokines, such as IFN- $\gamma$, which is known to play a pivotal role in CAV development. ${ }^{18,19}$ Furthermore, donor hearts transplanted into CD8 -/knockout recipients had markedly less severe intimal lesions. Therefore the findings of this study demonstrate an important role for $\mathrm{CD}^{+}$lymphocytes in $\mathrm{CAV}$ development.

In acute cellular rejection of allografts, it is currently accepted that both $\mathrm{CD}^{+}$and $\mathrm{CD} 8^{+}$lymphocytes can mediate cellular injury. ${ }^{20,21}$ In chronic rejection of allografts, only the role of $\mathrm{CD}^{+}$lymphocytes is well established. ${ }^{22-24}$ However, there is limited and yet conflicting information on the role of $\mathrm{CD}^{+}$lymphocytes in chronic rejection. ${ }^{5,9,10}$ The findings of this study substantiate a significant contributory role for $\mathrm{CD}^{+}$lymphocytes in CAV by demonstrating (1) a temporal relationship between $\mathrm{CD} 8^{+}$lymphocyte recruitment and CAV development, (2) the presence of activated graft-infiltrating $\mathrm{CD} 8^{+}$lymphocytes, (3) the production of IFN- $\gamma$ by graft-infiltrating $\mathrm{CD} 8^{+}$lymphocytes, and (4) a marked decline in intimal lesion development in the absence of $\mathrm{CD} 8^{+}$lymphocytes.

To define the precise mechanism of $\mathrm{CD}^{+}$lymphocyte contribution to CAV development, we assayed the graftinfiltrating $\mathrm{CD}^{+}$lymphocytes for their known effector functions. $\mathrm{CD} 8^{+}$lymphocytes render their effector function directly, by inducing vessel wall injury (cytotoxicity), or indirectly, through the secretion of cytokines. Among the inflammatory cytokines, IFN- $\gamma$ has been shown to play a pivotal role in CAV development. ${ }^{18,19}$ The serologic neutralization or genetic absence of IFN- $\gamma$ has been shown to markedly reduce the extent of CAV in murine models. ${ }^{18,19}$ IFN- $\gamma$ may contribute to CAV development directly, through the activation of macrophages, or indirectly, through the upregulation of donor MHC antigens, with subsequent T-lymphocyte activation. ${ }^{18,19,22-25}$ Moreover, Tellides and colleagues ${ }^{26}$ have recently reported that IFN- $\gamma$ alone can induce arteriosclerotic changes in either swine or human carotid loops transplanted into immunodeficient mouse recipients. The current study provides evidence that the mechanism of $\mathrm{CD} 8^{+}$lymphocyte's contribution to $\mathrm{CAV}$ development is through both cytotoxic activity and elaboration of IFN- $\gamma$.

The findings of this study are especially timely and relevant, given the recent reported observations with costimulatory blockade therapy. ${ }^{27-30}$ Costimulatory molecule signaling is required to activate $\mathrm{T}$ lymphocytes. ${ }^{30}$ Significant strides have been made toward donor-specific tolerance through costimulatory blockade therapy. ${ }^{27-30}$ Given the central role of $\mathrm{CD}^{+}$lymphocytes in both acute and chronic rejection, this form of therapy has been con- 
ventionally directed against $\mathrm{CD} 4^{+}$lymphocyte costimulatory molecules, such as CD28 and CD40 ligand. Multiple experimental and, more recently, clinical studies have demonstrated the efficacy of costimulatory blockade in preventing acute rejection and prolonging allograft survival. ${ }^{27-30}$ However, long-lasting allografts still demonstrate manifestations of chronic rejection, ultimately leading to graft failure. ${ }^{20-23}$ Given the efficacy of costimulatory blockade in controlling $\mathrm{CD}^{+}$lymphocyte alloreactivity, it has been suggested that $\mathrm{CD}^{+}$lymphocytes may be responsible for the development of chronic rejection in the aforementioned studies. ${ }^{12,29-30}$ The findings of the current study substantiate a participating role for $\mathrm{CD} 8^{+}$lymphocytes in the pathogenesis of chronic rejection.

Optimal activation and proliferation of $\mathrm{CD}^{+}$lymphocytes, like $\mathrm{CD}^{+}{ }^{+}$lymphocytes, require the delivery of signals through both the T-cell receptor and a costimulatory molecule. ${ }^{28}$ Recent reports suggest that $\mathrm{CD} 8^{+}$lymphocytes can be activated independently of CD40 ligand and CD28 costimulatory pathways. ${ }^{13,31,32} \mathrm{CD} 8^{+}$lymphocyte activation may include the use of alternate costimulatory pathways, including an inducible co-stimulator (ICOS), intercellular adhesion molecule 1 (ICAM-1), and 4-1BB. ${ }^{33-36}$ We have recently observed that the costimulatory molecule 4-1BB provides preferential $\mathrm{CD} 8^{+}$lymphocyte costimulation in the MHC class II mismatched model system (unpublished data). The 4-1BB receptor, a member of the tumor necrosis factor receptor family, is rapidly expressed on $\mathrm{T}$ lymphocytes after antigen/T-cell receptor binding. ${ }^{34,36}$ In vitro studies illustrate that 4-1BB costimulation markedly enhances $\mathrm{CD}^{+}$lymphocyte proliferation, IFN- $\gamma$ production, and cytotoxicity. ${ }^{34,36}$ Given the importance of $\mathrm{CD} 8^{+}$ lymphocytes in chronic rejection, blockade of $\mathrm{CD}^{+} 1 \mathrm{ym}-$ phocyte-specific costimulatory molecules may be a necessary adjunct to the current costimulatory blockade regimen in preventing chronic rejection.

In conclusion, this study confirms the role of $\mathrm{CD}^{+}$lymphocytes and offers a mechanism for their contribution to chronic rejection. Knowledge of the precise contributions of $\mathrm{CD}^{+}$lymphocytes in CAV development will provide a framework for the design of rational therapies for chronic rejection in all solid organ transplants. Specifically, combination therapies that target $\mathrm{CD} 8^{+}$lymphocytes, in addition to $\mathrm{CD}^{+}$lymphocytes, with costimulatory molecule blockade, may prove necessary in the prevention of chronic rejection.

\section{References}

1. Schroeder JS, Gao SZ, Hunt SA, Stinson EB. Accelerated graft coronary artery disease: diagnosis and prevention. J Heart Lung Transplant. 1992;11(suppl):S258

2. Kobashigawa JA, Katznelson S, Laks H, et al. Effect of pravastatin on outcomes following cardiac transplantation. $N$ Engl J Med. 1995;333:621

3. Oh GY, Norman DJ, Hosenpud JD, Hershberger RE, Ratkovee RM, Cobonoglu A. Heart transplantation in patients with previous cardiac operations: excellent clinical results. J Thorac Cardiovasc Surg. 1994; 108:1149.

4. Paul LC, Davidoff A, Benediktsson H. Cardiac allograft atherosclerosis in the rat: the effect of histocompatibility factors, cyclosporine, and an angiotensin-converting enzyme inhibitor. Transplantation. 1994;57:1767.

5. Shi C, Lee WS, He Q, et al. Immunologic basis of transplant-associated arteriosclerosis. Proc Natl Acad Sci U S A. 1996;93:4051.

6. Hosenpud JD, Everett JP, Morris TE, Mauck KA, Shipley GD, Wagner CR. Cardiac allograft vasculopathy: association with cellmediated but not humoral alloimmunity to donor-specific vascular endothelium. Circulation. 1995;92:205.

7. Russell PS, Chase CM, Colvin RB. Contributions of cellular and humoral immunity to arteriopathic lesions in transplanted mouse hearts. Transplant Proc. 1997;29:2527.

8. Räisänen-Sokolowski A, Glysing-Jensen T, Mottram PL, Russell ME. Sustained anti-CD4/CD8 treatment blocks inflammatory activation and intimal thickening in mouse heart allografts. Arterioscler Thromb Vasc Biol. 1997; 17:2115.

9. Allan JS, Choo JK, Vesga L, et al. Cardiac allograft vasculopathy is abrogated by anti-CD8 monoclonal antibody therapy. Ann Thorac Surg. 1997;64:1019.

10. Clark-Forbes RD, Zheng SX, Gomersall M, al-Saffar M, Guttmann RD. Evidence that recipient CD8+ T cell depletion does not alter development of chronic vascular rejection in a rat heart allograft model. Transplantation. 1994;57:1238.

11. Ardehali A, Billingsley A, Laks H, Drinkwater DC Jr, Sorensen TJ, Drake TA. Experimental cardiac allograft vasculopathy in mice. $J$ Heart Lung Transplant. 1993;12:730.

12. Yun JJ, Fischbein MP, Laks H, et al. Early and late chemokine production in cardiac allograft vasculopathy. Transplantation. 2000;69:2515.

13. Fischbein MP, Ardehali A, Yun J, et al. CD40 signaling replaces CD4+ lymphocytes and its blocking prevents chronic rejection of heart transplants. J Immunol. 2000;165:7316.

14. Corry RJ, Winn HJ, Russell PS. Primarily vascularized allografts of hearts in mice: the role of $\mathrm{H}-2 \mathrm{D}, \mathrm{H}-2 \mathrm{~K}$, and non-H-2 antigens in rejection. Transplantation. 1973;16:343.

15. Armstrong AT, Strauch AR, Starling RC, et al. Morphometric analysis of neointimal formation in murine cardiac grafts. Transplantation. 1997;63:941.

16. Salomon RN, Hughes CC, Schoen FJ, Payne DD, Pober JS, Libby P. Human coronary transplantation-associated arteriosclerosis: evidence for a chronic immune reaction to activated graft endothelial cells. Am J Pathol. 1991;138:791.

17. Mobley J, Dailey M. Regulation of adhesion molecule expression by CD8 $\mathrm{T}$ cells in vivo. I. Differential regulation of gp90 ${ }^{\mathrm{MEL}-14}$ (LECAM-1), Pgp-1, LFA-1, and VLA-4 $\alpha$ during the differentiation of cytotoxic T lymphocytes induced by allografts. J Immunol. 1992; 148:2348.

18. Nagano H, Mitchell RN, Taylor MK, Hasegawa S, Tilney NL, Libby $\mathrm{P}$. Interferon-gamma deficiency prevents coronary arteriosclerosis but not myocardial rejection in transplanted mouse hearts. J Clin Invest. 1997; 100:550.

19. Nagano H, Libby P, Taylor MK, et al. Coronary arteriosclerosis after T-cell-mediated injury in transplanted mouse hearts: role of interferon-gamma. Am J Pathol. 1998;152:1187.

20. Bishop DK, Shelby J, Eichwald EJ. Mobilization of T lymphocytes following cardiac transplanation: evidence that CD4 positive cells are required for cytotoxic T lymphocyte activation, inflammatory endothelia development, and acute allograft rejection. Transplantation. 1992;53:849.

21. Orosz CG, Wakely E, Sedmak DD, Bergese SD, VanBuskirk AM Prolonged murine cardiac allograft acceptance: characteristics of persistent active alloimmunity after treatment with gallium nitrate versus anti-CD4 monoclonal antibody. Transplantation. 1997;63:1109.

22. Räisänen-Sokolowski A, Mottram PL, Glysing-Jensen T, Satoskar A, Russell ME. Heart transplants in interferon-gamma, interleukin 4, and interleukin 10 knockout mice: recipient environment alters graft rejection. J Clin Invest. 1997;100:2449.

23. Raisanen-Sokolowski A. Reduced transplant arteriosclerosis in murine cardiac allografts placed in interferon-gamma knockout recipients. Am J Pathol. 1998;152:359. 
24. Russell PS, Chase CM, Winn HJ, Colvin RB. Coronary atherosclerosis in transplanted mouse hearts. III. Effects of recipient treatment with a monoclonal antibody to interferon-gamma. Transplantation. 1994;57:1367.

25. Russell ME, Wallace AF, Hancock WW, et al. Upregulation of cytokines associated with macrophage activation in the Lewis-toF344 rat transplantation model of chronic cardiac rejection. Transplantation. 1995;59:572.

26. Tellides G, Tereb DA, Kirkiles-Smith NC, et al. Interferon-gamma elicits arteriosclerosis in the absence of leukocytes. Nature. 2000;403:207.

27. Kirk AD, Burkly LC, Batty DS, et al. Treatment with humanized monoclonal antibody against CD154 prevents acute rejection in nonhuman primates. Nat Med. 1999;5:686.

28. Larsen CP, Elwood ET, Alexander DZ, Ritchie SC, Hendrix R, Tucker-Burden $\mathrm{C}$, et al. Long-term acceptance of skin and cardiac allografts after blocking CD40 and CD28 pathways. Nature. 1996;381:434.

29. Hancock WW, Sayegh MH, Zheng XG, Peach R, Linsley PS, Turka LA. Costiumlatory function and expression of CD40 ligand, CD80, and CD86 in vascularized murine cardiac allograft rejection. Proc Natl Acad Sci U S A. 1996;93:13967.
30. Schwartz RH. Costimulation of $\mathrm{T}$ lymphocytes: the role of $\mathrm{CD} 28$, CTLA-4, and B7/BB1 in interleukin-2 production and immunotherapy. Cell. 1992;71:1065.

31. Ensminger SM, Witzke O, Spriewald BM, et al. CD8+ T cells contribute to the development of transplant arteriosclerosis despite CD154 blockade. Transplantation. 2000;69:2609.

32. Jones ND, Van Maurik A, Hara M, et al. CD40-CD40 ligand-independent activation of $\mathrm{CD} 8+\mathrm{T}$ cells can trigger allograft rejection. $J$ Immunol. 2000;165:1111.

33. Hutloff A, Dittrich AM, Beier KC, et al. ICOS is an inducible T-cell costimulator structurally and functionally related to CD28. Nature. 1999;397:263.

34. Saoulli K, Young-Lee S, Cannons JL, et al. CD28-independent TRAF2-dependent costimulation of resting T cells by 4-1BB ligand. $J$ Exp Med. 1998;187:1849.

35. Deeths MJ, Meshcer MF. ICAM-1 and B7-1 provide similar but distince costimulation for CD8+ T cells, while CD4+ T cells are poorly costimulated by ICAM-1. Eur J Immunol. 1999;29:45.

36. Shuford WW, Klussman K, Tritchler DD, Loo DT. 4-1BB costimulatory signals preferentially induce $\mathrm{CD} 8+\mathrm{T}$ cells proliferation and leads to amplification in vivo of cytotoxic T cell responses. J Exp Med. 1997;186:47. 